\title{
O CÍRCULO HERMENÊUTICO GADAMERIANO E O MILAGRE DA COMPREENSÃO
}

\author{
THE GADAMERIAN HERMENEUTIC CIRCLE AND THE MIRACLE OF \\ UNDERSTANDING
}

Brenda dos Santos Menezes ${ }^{1}$

RESUMO: O objetivo desse trabalho é analisar a hermenêutica filosófica do filósofo HansGeorg Gadamer, com ênfase em sua principal obra, "Verdade e Método: elementos de uma hermenêutica filosófica (1960)". Possuindo enorme influência de Heidegger, Gadamer transpõe para sua teoria as ideias desse filósofo sobre linguagem, história, pensamento, e experiência humana, fundamentando assim, sua obra hermenêutica e filosófica. A hermenêutica gadameriana inova, de certa forma, ao apresentar uma nova abordagem no modo de interpretação, na qual grande parte de concepções dogmáticas são debeladas. Para tanto, é buscado na grande contribuição de Gadamer para a hermenêutica: o conceito de círculo-hermenêutico e a importância do mesmo para o processo de compreensão.

Palavras-chave: Círculo-Hermenêutico. Gadamer. Hermenêutica.

\begin{abstract}
The aim of this paper is to analyze a philosophical hermeneutic of the philosopher Hans-Georg Gadamer, with emphasis on his main work, "Truth and Method: Elements of a Philosophical Hermeneutic (1960)". Having enormous influence of Heidegger, the Gadamer transposes to his theory the ideas that address philosophy, history, thought and human experience, thus grounding his hermeneutic and philosophical work. Gadamerian hermeneutics innovates, in a way, by presenting a new approach to the mode of interpretation, in which much of the dogmatic conceptions are tackled. To this end, a great contribution from Gadamer to hermeneutics is sought: the concept of hermeneutic circle and its importance for the process of understanding.
\end{abstract}

Keywords: Circle-Hermeneutic. Gadamer Hermeneutics.

${ }^{1}$ Graduanda de Filosofia pela Universidade Federal do Maranhão. E-mail:brenda_menezes0@live.com 


\section{INTRODUÇÃO}

Hans-Georg Gadamer foi um importantíssimo filósofo alemão do século XX considerado como um dos maiores expoentes da hermenêutica. Teve grande notoriedade em diversas áreas do conhecimento, desde à estética aos conhecimentos jurídicos.

Ao analisar o processo histórico e suas respectivas interpretações promovidas por certos movimentos de estudos bíblicos, Gadamer viu-se levado a impetrar no problema da intepretação e da linguagem, daí, pois, surgiu sua principal obra: "Verdade e Método" (1960).

Entre os assuntos trabalhados na obra, destaca-se o conceito de "pré-compreensão", pois é a partir desta que o indivíduo compreende o texto que está estudando. Daí, pois, o autor determinará como deve-se proceder para entender o sentido do texto. É importante ressaltar que para Gadamer, o texto é resultado de um contexto histórico ligado ao dinamismo interpretativo.

\section{O CÍRCULO HERMENÊUTICO}

Etimologicamente, o termo "compreensão origina-se do latim comprehensionis. Entende-se como compreensão a ação ou feito de compreender, entender e assimilar algo, ou alguma coisa. A partir desse processo cognitivo, qual se faz necessário a interpretação do objeto de estudo para que, posteriormente, possa vir a ser compreendido pelo indivíduo.

Nesse sentido, o ciclo hermenêutico segundo Gadamer objetiva apresentar uma teoria da compreensão a partir do diálogo. Ele visa a superação de interpretações distorcidas sob os "preconceitos" propondo através disso uma compreensão adequada da finitude, a qual não se limite a nossa estrutura enquanto ser, o qual traz a visão de Heidegger, mas uma visão da compreensão da nossa estrutura enquanto ser histórico.

Em Verdade e Método, Gadamer traz uma aclaração sobre o conceito de círculo hermenêutico, tal conceito advindo da influência heideggeriana, qual seja:

"O círculo não deve ser degradado a círculo vicioso, mesmo que este seja tolerado. Nele vela uma possibilidade positiva do conhecimento mais originário, que, evidentemente, só será compreendido de modo adequado, 
quando a interpretação compreender que sua tarefa primeira, constante e última permanece sendo a de não receber de antemão, por meio de uma 'feliz ideia' ou por meio de conceitos populares, nem a posição prévia, nem a visão prévia, mas em assegurar o tema científico na elaboração desses conceitos a partir da coisa mesma". (GADAMER, 1998, p. 401).

A principal ideia do pensamento de Gadamer reside em sua Hermenêutica Filosófica, na qual perpassam outros aspectos peculiares de seus estudos e escritos, cuja contribuição de seus trabalhos vai para além da Filosofia, alcançando universos como o da linguística e o da educação, por exemplo. É importante frisar que, embora tenha sido

Antes de falar a respeito da Hermenêutica Filosófica Gadameriana, faz-se necessário registrar que, apesar de Gadamer ter sido aluno de Heidegger e consequentemente influenciado pelo mesmo, buscando neste algumas de suas linhas diretivas, a passagem da Hermenêutica de um para outro não se dá instantaneamente. Heidegger, por um lado, baseava-se com maior densidade na Hermenêutica da existência, Gadamer, por outra perspectiva terá como foco a observação.

É possível afirmar que o pensamento do filósofo vai buscar complementar a teoria ontológico-existencial de Heidegger, ampliando assim, essa perspectiva por meio da linguística como um caminho fundamental visando a compreensão. Por outra perspectiva, não se pode esquecer da importância do diálogo para toda interação construtiva que se espera obter, já que nessa interação dialógica, ou, como diz Gadamer, no diálogo Hermenêutico, há uma pretensão de verdade na qual a expressão só terá confirmação ou negação quando confrontada com o outro sujeito da relação, já que o pensar não deve ser algo isolado, mas levado à abertura dos interlocutores, pois só por meio do confronto de ideias é possível obter a construção de algo substancial, visto que "o verdadeiro carisma do diálogo está presente na espontaneidade viva do perguntar e do responder, do dizer e do deixar-se dizer” (GADAMER, 1998, p.131).

Gadamer elucida que a reflexão hermenêutica de Heidegger tem o seu ponto alto que é demonstrar que o círculo tem um sentido ontológico positivo e que toda interpretação deve proteger-se das "felizes ideias" (preconceitos existentes). Ademais, evidencia que a compreensão somente alcança sua verdadeira possibilidade, quando as opiniões prévias, com as quais ela inicia, 
não são arbitrárias, isto é, o intérprete não se dirige aos textos diretamente, a partir da opinião prévia que está subjacente em si, mas que examine tais opiniões quanto à sua legitimação, quanto à sua origem e validez.

No entanto, vale ressaltar que Gadamer reconhece que as opiniões não podem ser entendidas de maneira arbitrária, pois ao ouvir alguém ou quando se empreende em uma leitura, não é necessário que se esqueça todas as opiniões prévias sobre seu conteúdo e todas as opiniões próprias, o que o autor "exige" para a compreensão de um texto, em princípio, é que o leitor esteja disposto a deixar o texto dizer alguma coisa por si. Para o filósofo a consciência hermenêutica tem que se mostrar receptiva, desde o princípio, para a alteridade do texto, assim o leitor deve dá conta de suas próprias antecipações, para que o texto possa apresentar-se em sua alteridade e obtenha assim a possibilidade de confrontar sua verdade com as próprias opiniões prévias.

Nesse sentido, Gadamer assevera que não há compreensão que seja livre de todo preconceito, mas a superação de todo preconceito liberará primeiramente o caminho para uma compreensão adequada da finitude, que domina não apenas o nosso ser-homens, mas também nossa consciência histórica.

Destaca-se que o pensador aborda o preconceito através do Iluminismo. $O$ autor descreve que segundo o movimento existem os preconceitos gerados pelo respeito humano e os preconceitos por precipitação. Essa divisão tem seu fundamento na origem dos preconceitos, na perspectiva das pessoas que os cultivam, ou seja, o que nos induz a erros é o respeito pelos outros, por sua autoridade, ou a precipitação que existe em nós mesmos.

O Iluminismo crítica, assim, a tradição escrita, a Sagrada Escritura como qualquer outra informação histórica, sendo assim, segundo o movimento não podem valer por si mesmas. Antes, a possibilidade de que a tradição seja verdade depende da credibilidade que a razão lhe concede. A fonte última de toda autoridade já não é a tradição, mas a razão. O que está escrito não precisa ser verdade. 
Diante dessa crítica iluminista que traz o preconceito sob a ideia de uma autoconstrução absoluta da razão, e que apresenta o preconceito como limitador, Gadamer afirma que se quer fazer justiça ao modo de ser finito e histórico do homem, é necessário levar a cabo uma drástica reabilitação do conceito de "preconceito" e reconhecer que existem preconceitos legítimos. O pensador reavalia o conceito de "preconceito", entendendo como pré-conceitos as ideias que tecem nossa pré-compreensão, as quais continuamente subjazem à prova da experiência.

Assim, Gadamer diz ser inaceitável essa visão negativa do preconceito sob a visão de autoridade, descrito pelo movimento iluminista. O ideal iluminista procurou descartar tudo aquilo que o impedia de seguir adiante em seus anseios progressistas, e se valeu de uma interpretação unilateral para pôr de lado qualquer tipo de preconceito, por caracterizá-lo como pensamento infundado, irracional, trazendo descrédito à autoridade e à tradição.

Contudo, Gadamer diz ser impossível estarmos isentos de quaisquer preconceitos diante da nossa capacidade de especulação; são também eles que nos impulsionam a ir ao encontro do que seja verdadeiro. Não longe disso, a falta de fundamentação poderia acarretar num descrédito daquilo a que se faz alusão.

O Iluminismo quis fundamentar tudo na razão, e fez dela um método para alcançar seus ideais, porém se esqueceu de que não se pode fazer uma busca partindo do zero, sem noções que sejam prévias. Quando se busca algo, é pelo fato de se ter sido impulsionado anteriormente.

O pensador afirma que o "pré-conceito" é caminho para o conhecimento e tem sua validade e utilidade, mas não se trata de tê-lo ou não. É, antes de mais nada, uma posição que tomamos ante o que nos apresenta, podendo assumir um juízo positivo ou negativo. Já não é mais possível ficar indiferente quanto ao preconceito. Sua parcela representa muito em nossos atos e em nosso jeito de ver o mundo. Cabe a nós fazermos dele bom uso, seja nos âmbitos religiosos, étnicos, raciais, sociais, econômicos. O escritor recomenda dizer sim ao preconceito responsável, uma compreensão hermenêutica positiva, tendo a tradição, conhecimento anterior, como base investigativa diante da dúvida. 
Gadamer apresenta a tradição como algo que carrega o intérprete, como a historicidade dentro da qual a compreensão está desde sempre lançada, e elucida que mesmo a interpretação que parece mais objetiva vem a partir de uma tradição. Todas as respostas a que uma boa interpretação pode chegar seriam ainda assim respostas a perguntas que foram lançadas na tradição, perguntas que em um dado momento histórico apresentam-se como fundamentais.

O Ilustre pensador ressalta que a regra hermenêutica, baseia-se na compreensão do todo a partir do individual e o individual a partir do todo, relembra, o autor, que é uma regra que procede da antiga retórica e que a hermenêutica moderna transferiu da arte de falar para a arte de compreender. O movimento da compreensão vai constantemente do todo à parte e desta ao todo. A função é alargar a unidade do sentido compreendido em círculos convergentes. O critério correspondente para a correção da compreensão é sempre a concordância de cada particularidade com o todo. Quando não há tal concordância, isso significa que a compreensão frustrou.

Assim, em Verdade e Método, Gadamer fala sobre a tentativa de compreender um texto. Para ele quando procuramos entender um texto, não nos deslocamos até a constituição psíquica do autor, mas, se quisermos falar de deslocar-se, o fazemos tendo em vista a perspectiva sob a qual o outro ganhou a sua própria opinião. E isso não quer dizer outra coisa, senão que procuramos fazer valer o direito objetivo do que o outro diz. Quando procuramos entender, fazemos inclusive o possível para reforçar os seus próprios argumentos e isso se torna mais patente na compreensão do escrito. É tarefa da hermenêutica explicar esse milagre da compreensão, que não é uma comunhão misteriosa das almas, mas uma participação num sentido comum.

De acordo com a visão de Gadamer a hermenêutica sempre se propôs como tarefa restabelecer o entendimento alterado ou inexistente. O círculo, portanto, não é de natureza formal. Não é nem objetivo nem subjetivo, descreve, porém, a compreensão como a interpretação do movimento da tradição e do movimento do intérprete. A antecipação de sentido, que guia a nossa compreensão de um texto, não é um ato da subjetividade, já que se determina a partir da comunhão que nos une com a tradição.

Entretanto, sob a perspectiva do autor nossa relação com a tradição está submetida a um processo de contínua formação. Não se trata simplesmente de uma pressuposição, sob a qual nos encontramos sempre, nós mesmos vamos instaurando-a, na medida em que compreendemos, em que participamos do acontecer da tradição e continuamos determinando-o, assim, a partir de nós 
próprios. O círculo da compreensão não é, portanto, de modo algum, um círculo "metodológico", pois isso sim, descreve um momento estrutural ontológico da compreensão.

Vale salientar o dizer de Gadamer que toda compreensão, possui uma nova transcendência hermenêutica que é denominada como "concepção prévia da perfeição". Ele evidencia que isso é, claramente, uma pressuposição formal, que orienta toda compreensão. $\mathrm{O}$ que ele pretende dizer é que fazemos tal pressuposição da perfeição quando lemos um texto, e somente quando esta se manifesta como insuficiente, isto é, quando o texto não é compreensível, duvidamos da transmissão e procuramos adivinhar como pode ser remetida.

Essa concepção antecipada da perfeição, que domina nessa compreensão, encontra-se, em cada fato, determinada com relação a algum conteúdo, histórico, cultural. Não se pressente somente uma unidade imanente de sentido que possa guiar o leitor, mas que a compreensão deste esteja guiada constantemente por expectativas de sentido transcendente, que surgem de sua relação com a verdade daquilo a que o texto intenciona.

Nesse sentido, compreender em primeiro lugar significa sentir-se entendido na coisa, e somente secundariamente destacar e compreender a opinião do outro como tal. Assim, a primeira de todas as condições hermenêuticas é a pré-compreensão que surge do ter de se haver com a coisa em questão. Assim, não pode haver qualquer interpretação desprovida de pressupostos. A compreensão, posto que seja uma estrutura básica historicamente acumulada e historicamente operativa, está subjacente em cada leitor, observador.

Segundo a ótica do autor entende-se que diante da impossibilidade de existir uma interpretação sem pressupostos, pode-se inferir, que a noção de interpretação absolutamente correta é um ideal impensável.

Gadamer, afirma que todos pertencemos a um contexto, seja ele histórico ou cultural, o qual nos fornece os pressupostos para nos relacionarmos com o mundo. Sempre que vamos ao encontro do novo, temos antecipadamente pré-compreensões que favorecem a compreensão daquilo que até então era estranho e desconhecido.

A compreensão procede precisamente do encontro com a tradição. Pois o que incita à compreensão deve ter-se feito valer já, de algum modo, em sua própria alteridade. Esta é a condição hermenêutica suprema. Ela exige com isso a de suspender por completo os próprios preconceitos. Porém, a suspensão de todo juízo e de todo preconceito, visto logicamente, tem a estrutura da pergunta. 
A natureza da pergunta é a de abrir e manter abertas possibilidades. Dessa maneira quando um preconceito se torna questionável face ao que nos apresenta outra pessoa ou um texto isso não quer dizer que ele seja simplesmente deixado de lado e que o outro ou o diferente venha a substituí-lo imediatamente em sua validez.

\section{CONSIDERAÇÕES FINAIS}

A grande colaboração da hermenêutica filosófica gadameriana, é a possibilidade de permitir pensar um outro pensar. Isto é, um pensar que pensa o outro pensar que na verdade é o próprio ato do pensamento que pensa o pensamento.

O fenômeno, próprio da linguagem, evidencia que o pensamento do pensamento se desenvolve em uma epistemologia da compreensão que se inicia na pré-compreensão. O "précompreender" por sua vez, estabelece um critério do entendimento que não é orientado pela tecnicidade.

Por seu turno pode-se concluir que Gadamer trouxe a compreensão da sua hermenêutica filosófica junto com Martin Heidegger, deixando a hermenêutica de ser um simples método das ciências do espírito, passando a ser compreendida por meio da interpretação dentro da tradição. 


\section{REFERÊNCIAS}

GADAMER, Hans-Georg. Verdade e Método: Traços fundamentais de uma hermenêutica filosófica. Tradução de Flávio Paulo Meurer. 2. ed. Petrópolis: Vozes, 1998.

LAWN, Chris. Compreender Gadamer. Tradução de Hélio Magri Filho. Petrópolis: Vozes, 2007

OLIVEIRA, Daniela Rezende de; MOURA, Rafael Soares Duarte de (Ed.). Apontamentos acerca da pré-compreensão e da compreensão nas Teorias Hermenêuticas de Martin Heidegger e Hans-Georg Gadamer e suas implicações no ato de julgar. Revista do Tribunal de Contas do Estado de Minas Gerais, Minas Gerais, v. 78, n. 1, p.1-16, mar. 2011. 